\title{
Design, Analysis and Optimization of A Slotted Microstrip Patch Antenna Array at Frequency 5.25 GHz for WLAN-SDMA System
}

\author{
Chandan Kumar Ghosh ${ }^{1}$ and Susanta Kumar Parui ${ }^{2}$ \\ ${ }^{1}$ Dr.B.C. Roy Engineering College, Jemua Road, Fuljhore, Durgapur-713206, India. \\ ${ }^{2}$ Bengal Engineering and Science University, Shibpur, India. \\ mcet_ckg@yahoo.com
}

\begin{abstract}
The design of array antenna is vital study for today's Wireless communication system to achieve higher gain, highly directional beam and also to counteract the effect of fading while signal propagates through various corrupted environments. In this study, the design and analysis of a (2x2) microstrip patch antenna array is introduced. It is designed to function in the $5.25 \mathrm{GHz}$ which corresponds to IEEE 802.11a (VSWR<2, data rate 54Mbps/ B.W $20 \mathrm{~dB}$ and S-parameters, $\mathrm{S}_{\mathrm{ij}}<-20 \mathrm{~dB}$ where $\mathrm{i} \neq \mathrm{j}$ ) wireless LAN application. It achieves single band functionality through additional slots to rectangular patch of dimension $18.8 \mathrm{~mm}$ by $24.4 \mathrm{~mm}$. The proposed antenna array is a high gain, low-cost, low weight base station antenna. The characteristic analyses such as return loss (RL), bandwidth, VSWR and radiation pattern of the prototype antenna array have been investigated both numerically and experimentally. In this investigation, VSWR less than 1.45 and bandwidth of $180 \mathrm{MHz}$ (For $\mathrm{RL}>-9.5 \mathrm{~dB}$ ) and antenna gain of $13.88 \mathrm{dBi}$ have been achieved. Both numerical and experimental studies have been carried out to optimize the distance between the antenna elements. The measured results have a good agreement with that of simulated results. The numerical study has been done by using Zeland make IE3D electromagnetic simulator and measurements have been done with the help of Agilent make N5230A, network analyzer.

Index Terms: Antenna array, Antenna gain, Slotted microstrip patch, Fringing field, Wireless LAN, IE3D electromagnetic simulator, antenna feed point, Array optimization.
\end{abstract}

\section{Introduction}

Over the last two decades the wireless communication system has experienced a significant growth from first generation $(1 \mathrm{G})$ analog voice signal to forthcoming forth generation $(4 \mathrm{G})$ mobile technology. The motto of $4 \mathrm{G}$ communication system is to provide Wi-Fi (Wireless Fidelity) communication network and high quality audio and video services. Today's technology requires high data rate and longer range to provide quality services to the users. For current mobile communication, the diversity scheme has already been implemented to mitigate the fading effects of multipath scenario [1], [2]. In a multipath rich wireless channel, deploying multiple antennas at both the transmitter and receiver achieves high data rate without increasing the total transmission power [3]. In this study, an antenna array has been design to improve the gain, antenna beam, bandwidth and reliability of the communication system. This is achieved as a result of the use of multiple antenna elements, exited through single feed point via the transmission line networks.

The array antenna structure is very interesting study and it is widely applicable to increase the range and reliability [4]-[6] of Wi-Fi LAN, Bluetooth, PDA (Personal Digital Assistants) DCS (Digital Communication System) and mostly in the field mobile communication. This article describes the design, analysis and simulation of single element and multi elements patch antenna array for recent wireless communication system which operates at $5.25 \mathrm{GHz}$ band. The antenna is designed, optimized and analyzed with commercially available IE3D electromagnetic simulator. In this investigation, a simple rectangular patch with rectangular slots in there different positions has been taken to achieve good performances. We focused on

Received: March 3, 2010. Accepted: May 19, 2010 
the antenna aspect of array system where four element microstrip patch configuration is proposed. Some good review articles are [7], [8], [9] and [10] where they did not optimized the distance between the antenna elements for reducing the effect of mutual coupling between the elements. But despite that they still give good introduction to the advantages and disadvantages of the system.

\section{Design Principles}

Initially the dimension of the single patch has been designed with three slots in three different positions with characteristic parameters of length (L), width (W) and thickness (t) as shown in Figure 1.

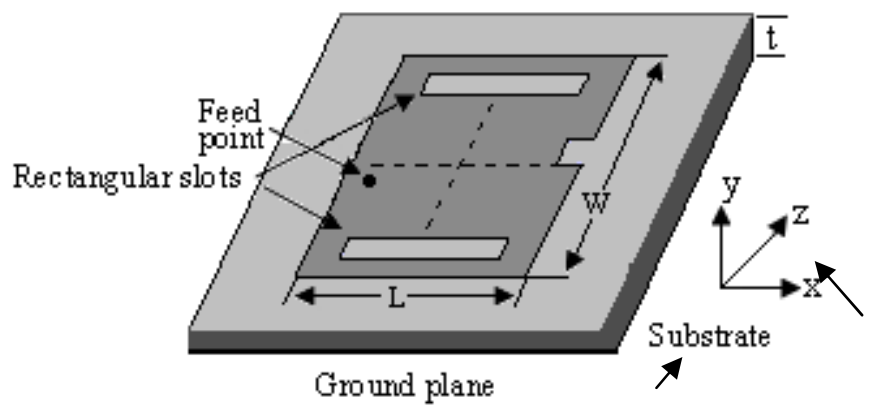

Figure 1. Geometry of a single element of the microstrip patch array.

To meet the actual design requirements i.e. operating frequency $5.25 \mathrm{GHz}$, beam pattern, band width and the radiation efficiency, some approximations have been taken. The calculations are based on transmission line model. The width and length of the microstrip patch have been calculated by the following formula [11]

$$
W=\frac{c}{2 f \sqrt{\frac{\epsilon_{\mathrm{r}+1}}{2}}}
$$

Where the required frequency $\mathrm{f}_{0}=5.25 \mathrm{GHz}, \mathrm{c}=3 \mathrm{e} 10 \mathrm{~cm} / \mathrm{s}$ and $\varepsilon_{\mathrm{r}}=2.2$. Substituting above values, the width of the patch (W) becomes $22.58 \mathrm{~mm}$. The effective length of the patch can be calculated with the help of equations (3) and (4).

$$
\begin{aligned}
& \mathrm{L}_{\text {eff }}=\frac{\mathrm{c}}{2 \mathrm{f}_{0} \sqrt{\epsilon_{\text {reff }}}} \\
& \epsilon_{\text {reff }}=\frac{\epsilon_{\mathrm{r}}+1}{2}+\frac{\epsilon_{\mathrm{r}}-1}{2}\left(\frac{1}{\sqrt{1+12 \mathrm{t}} / \mathrm{w}}\right)
\end{aligned}
$$

In this design, RT/duroid substrate has been used with substrate parameters are $\tan \delta=0.001$, thickness of the substrate, $\mathrm{t}=1.588 \mathrm{~mm}$. Substituting $\mathrm{W}=22.58 \mathrm{~mm}, \varepsilon_{\mathrm{r}}=2.2$ in equation (4) we get $\varepsilon_{\text {reff }}=1.925$. Hence $\mathrm{L}_{\text {eff }}=20.60 \mathrm{~mm}$. The length extension is to be calculated by (5)

$$
\Delta L=0.412 \mathrm{t} \frac{\left(\epsilon_{\text {reff }}+0.3\right)\left(\frac{\mathrm{w}}{\mathrm{t}}+0.264\right)}{\left(\epsilon_{\text {reff }}-0.258\right)\left(\frac{\mathrm{w}}{\mathrm{t}}+0.8\right)}
$$

Substituting $\varepsilon_{\text {reff }}=1.925$ and the values of $\mathrm{W}$ and $\mathrm{t}$, we get $\Delta \mathrm{L}=0.823 \mathrm{~mm}$. Now the actual length (L) of the patch is given by $\mathrm{L}=\mathrm{L}_{\text {eff }}-2 \Delta \mathrm{L}=20.60 \mathrm{~mm}-1.686 \mathrm{~mm}=18.91 \mathrm{~mm}$. Apart from this approximate calculation, the dimension has been slightly adjusted in order to achieve 
the desired frequency. Table 1 shows the detail dimensions of the patch, the slotted portions and the exact location of the feed point.

Table 1.

\begin{tabular}{|c|c|c|}
\hline Parameters of the patch & Calculated value & Actual value \\
\hline Width(W) & $22.58 \mathrm{~mm}$ & $24.4 \mathrm{~mm}$ \\
\hline Length(L) & $18.91 \mathrm{~mm}$ & $18.8 \mathrm{~mm}$ \\
\hline Horizontal slot dimension & - & $(9 \times 2)$ sq.mm \\
\hline Vertical slot dimension & - & $(2 \times 3.5)$ sq..mm \\
\hline Feed point & - & $(-7,-2)$ \\
\hline
\end{tabular}

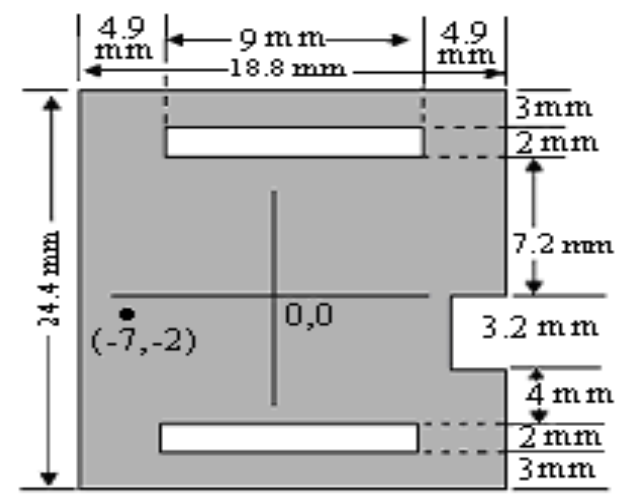

Figure 2. Design of single element of the array at $5.25 \mathrm{GHz}$

A number of feed points have been studied in this letter but the minimum RL and maximum radiation efficiency has been achieved at the feed location of $(-7,-2)$ and $(-7,-2)$. The characteristics of the array are slightly differ for the other three image points i.e $(7,2),(7,-2)$ and $-7,2$.

For the fundamental $\mathrm{TM}_{10}$ mode, the patch length should be slightly less than $\lambda / 2$, where $\lambda$ is the wavelength in the dielectric medium. Here, $\lambda$ is equal to $\lambda_{0} / \sqrt{\varepsilon_{0}}$, where $\lambda_{0}$ is the freespace wavelength and $\varepsilon_{0}$ is the effective dielectric constant of the patch. The designed antenna is a microstrip patch array with circularly polarization. When signal feed, a standing wave occurs but some of the fields will "leak out" around the edges of the patch. This is called fringing field. In the Figure 3, E-field on one side outside the patch is going into the patch and on the other side leaving the patch [12].

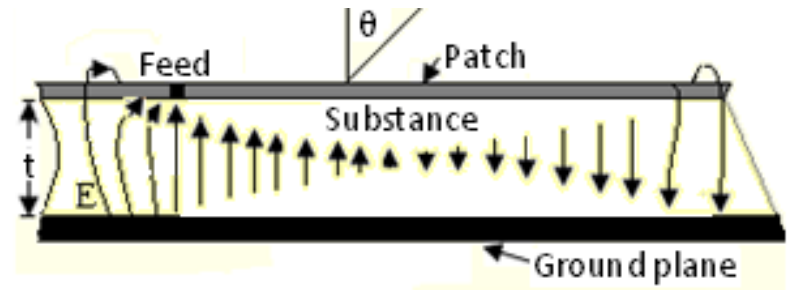

Figure 3. Side view of microstrip patch antenna showing E-fields.

\section{Design of Single Element}

Figure 4 shows the single element and double element of the array. The characteristics of the single element both simulated and measured are shown in the Figure 5, Figure 6, and Figure 7. 

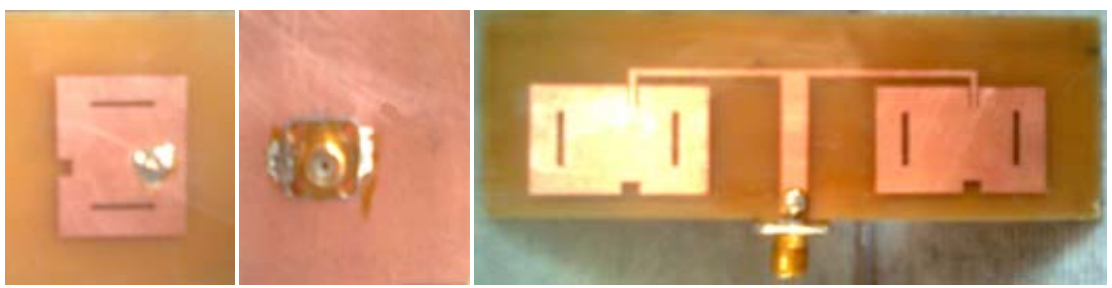

Figure 4. Fabrication of single element and two elements of the array

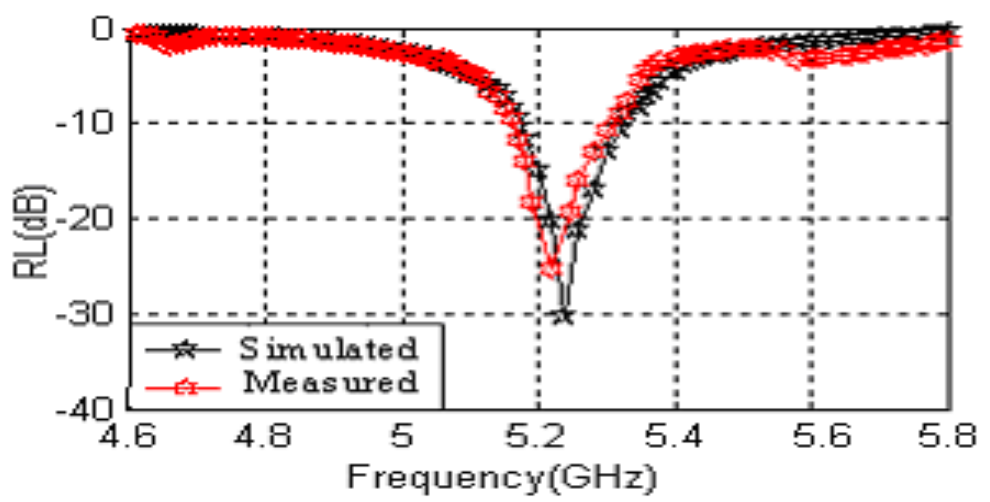

Figure 5. RL for single element of the array

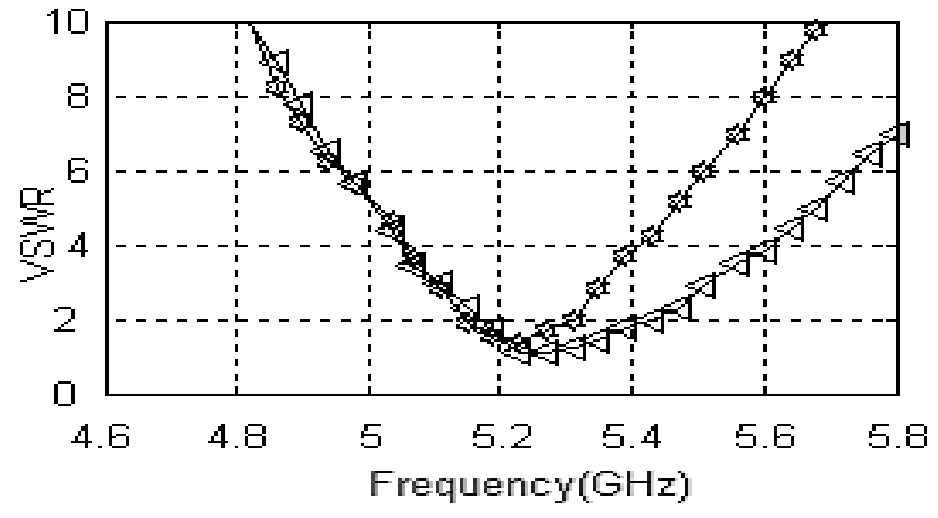

Figure 6. VSWR for single element of the array
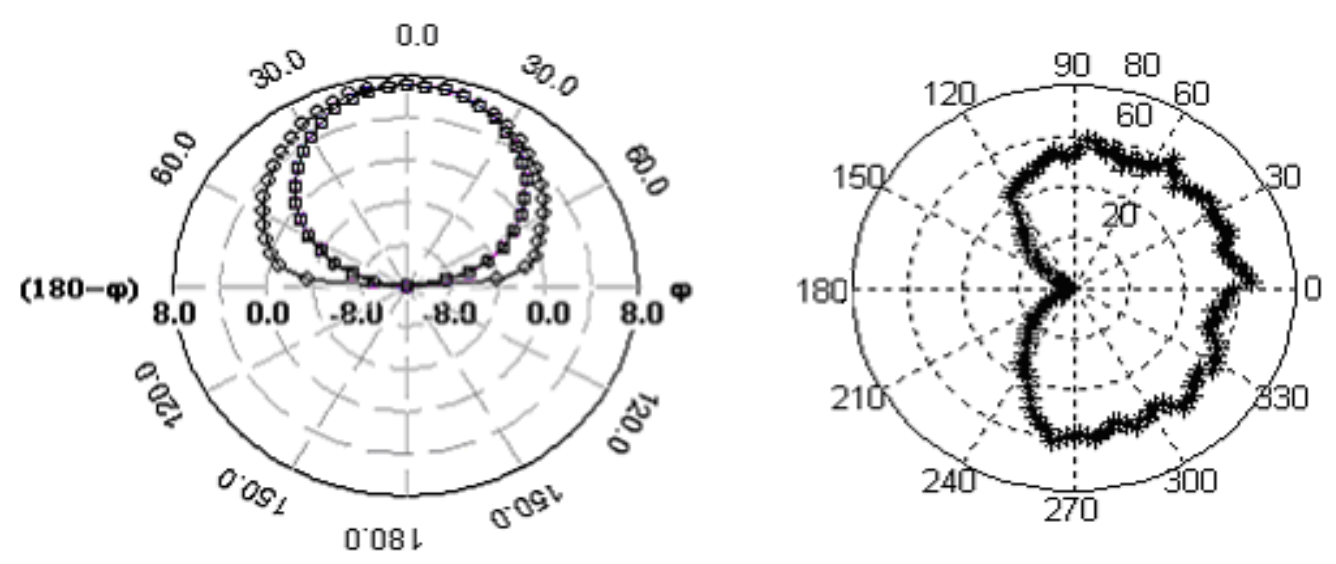

Figure 7. Elevation pattern gain simulated (left) for $\varphi=0 \mathrm{deg}$., $\varphi=90 \mathrm{deg}$.and measured radiation pattern (right) at frequency $5.25 \mathrm{GHz}$ 


\section{Array Design}

The most vital design of an antenna array is the feed network. This is constructed by first connecting two adjacent elements together with a transmission line and this can be calculated from (5). Now two separate groups, each containing two elements, need to be connected together. This is done with a transmission line drawn between the centers of the $0.54 \mathrm{~mm}$ wide transmission line.

$$
\begin{aligned}
& Z_{0}=\frac{\eta_{0}}{2 \pi \sqrt{\epsilon_{\mathrm{re}}}} \operatorname{In}\left(\frac{8 \mathrm{t}}{\mathrm{W}_{\mathrm{e}}}+0.25 \frac{\mathrm{W}_{\mathrm{e}}}{\mathrm{t}}\right), \text { for } \frac{\mathrm{W}}{\mathrm{t}} \leq 1 \\
& \text { and for } \frac{\mathrm{w}}{\mathrm{t}} \geq 1, Z_{0}= \\
& \frac{\eta_{0}}{\sqrt{\epsilon_{\mathrm{re}}}}\left[\frac{\mathrm{We}}{\mathrm{t}}+1.393+0.667 \ln \left(\frac{\mathrm{We}}{\mathrm{t}}+1.444\right)\right]^{-1}
\end{aligned}
$$

Where

$$
\begin{aligned}
& \frac{\mathrm{W}_{\mathrm{e}}}{\mathrm{t}}=\frac{\mathrm{W}}{\mathrm{t}}+\frac{1.25}{\pi} \frac{\mathrm{h}}{\mathrm{t}}\left[1+\ln \left(\frac{4 \pi \mathrm{W}}{\mathrm{h}}\right)\right], \text { for } \frac{\mathrm{w}}{\mathrm{t}} \leq \frac{1}{2 \pi} \\
& \text { and } \frac{\mathrm{W}_{\mathrm{e}}}{\mathrm{t}}=\frac{\mathrm{W}}{\mathrm{t}}+\frac{1.25}{\pi} \frac{\mathrm{h}}{\mathrm{t}}\left[1+\ln \left(\frac{2 \mathrm{t}}{\mathrm{h}}\right)\right], \text { for } \frac{\mathrm{w}}{\mathrm{t}} \geq \frac{1}{2 \pi} \\
& \epsilon_{\text {reff }}=\frac{\epsilon_{r}+1}{2} \cdot \frac{\epsilon_{r}-1}{2} F\left(\frac{\mathrm{w}}{\mathrm{t}}\right)-C
\end{aligned}
$$

and

$$
\begin{aligned}
& F\left(\frac{\mathrm{W}}{\mathrm{t}}\right)=\left(1+12 \frac{\mathrm{t}}{\mathrm{W}}\right)^{-\frac{1}{2}}+0.04\left(1-\frac{\mathrm{W}}{\mathrm{t}}\right)^{-1}, \text { for } \frac{\mathrm{W}}{\mathrm{t}} \leq 1 \\
& F\left(\frac{\mathrm{W}}{\mathrm{t}}\right)=\left(1+12 \frac{\mathrm{t}}{\mathrm{W}}\right)^{-\frac{1}{2}}, \text { for } \frac{\mathrm{W}}{\mathrm{t}} \geq 1 \\
& C=\frac{\varepsilon_{\mathrm{r}}-1}{4.6} \frac{\frac{\mathrm{h}}{\mathrm{t}}}{\sqrt{\frac{\mathrm{W}}{\mathrm{t}}}}
\end{aligned}
$$

$\mathrm{W}_{\mathrm{e}}$ is the effective width of the patch, $\mathrm{t}$ is the thickness of the dielectric substance, $\mathrm{Z}_{0}$ is the impedance of the transmission line and $\eta_{0}$ is the free space intrinsic impedance. The transmission line is split by using T-junction with equal power split. So both branches will receive input power which is as follows

$$
\mathrm{P}_{\text {in }}=\frac{1}{2} \frac{\mathrm{V}_{0}{ }^{2}}{2 \mathrm{Z}_{0}}
$$

If $\mathrm{P}_{1}$ and $\mathrm{P}_{2}$ be the output power, then

$$
\mathrm{P}_{1}=\mathrm{P}_{2}=\frac{1}{2} \frac{\mathrm{V}_{0}{ }^{2}}{2 \mathrm{Z}_{\text {out }}}=\frac{1}{2} \mathrm{P}_{\mathrm{in}}
$$

As equal power split is required, the out put impedance Zout of the transmission line using (14) and (15) is obtained as $Z_{\text {out }}=2 Z_{0}$ (16)

Typical impedance of a rectangular patch antenna varies from 100 to $400 \Omega$. From simulation results the impedance of each element is $192 \mathrm{ohms}$ and from (16) the impedance of transmission should be $192 / 2=96$ ohms. Equation (6) gives that the width of the thick line should be $3.1 \mathrm{~mm}$. The array is fed by a probe of diameter $1.2 \mathrm{~mm}$ in the middle of the thicker transmission line by using SMA of impedance $50 \mathrm{ohms}$. From (16) we get that the probe ideally should have an impedance of $96 / 2=48 \mathrm{ohms}$. 
The distance between the antenna elements has been optimized and fixed at $x_{1}=3 \mathrm{~cm}$. The isolation test has been carried out by placing the antenna elements at three different positions such as $2.2 \mathrm{~cm}, 2.5 \mathrm{~cm}$ and $3.0 \mathrm{~cm}$ respectively.From simulation results it is observed that to achieve better isolation the adjacent elements should be separated by the distance of at least $\lambda / 2$. In this design $\lambda / 2=2.857 \mathrm{~cm}$ and the element distance $\left(\mathrm{x}_{1}\right)$ has been fixed at $3.0 \mathrm{~cm}$. Figure 8 and Figure 9 show the geometry and the prototype of the proposed array.

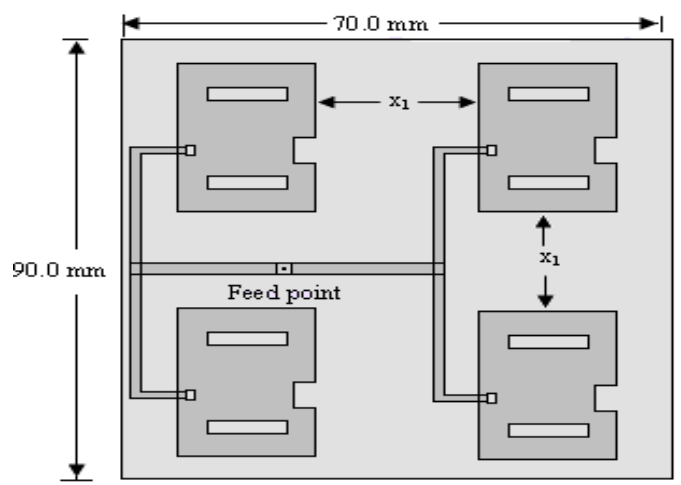

Figure 8. Geometry of (2x2) circularly polarized planar antenna array.
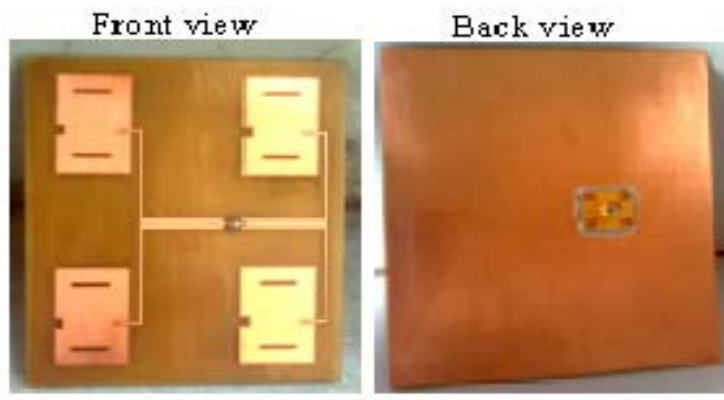

Figure 9. The prototype of the proposed array.

\section{Results of The Array}

\section{A. Radiation pattern}

The microstrip patch antenna radiates normal to its patch surface. So the elevation pattern for $\varphi=0$ and $\varphi=90$ degrees are important for the measurement. The simulated E-plane and Hplane pattern, 3D pattern view and the impedance characteristics of the array are illustrated in the Figure 10 and Figure 11. The measured and simulated values of VSWR are shown in the Figure 12. The simulated results for isolation between ports of the antenna elements with $\mathrm{x}_{1}=3.0 \mathrm{~cm}$ are shown in the Figure 14 . 

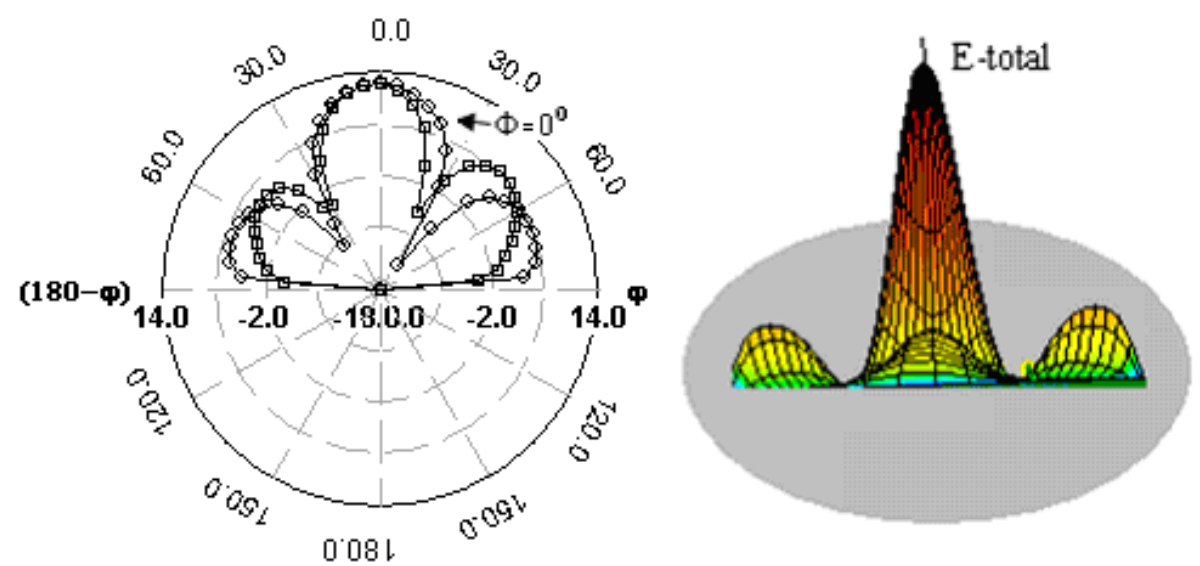

Figure 10. Simulated E-plane \& H-plane pattern and 3D view of the aray at $5.25 \mathrm{GHz}$.

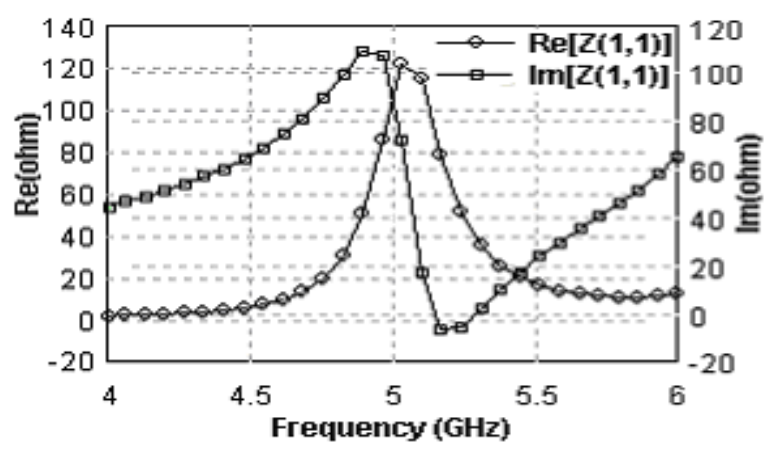

Figure 11. Impedance Characteristics of the array

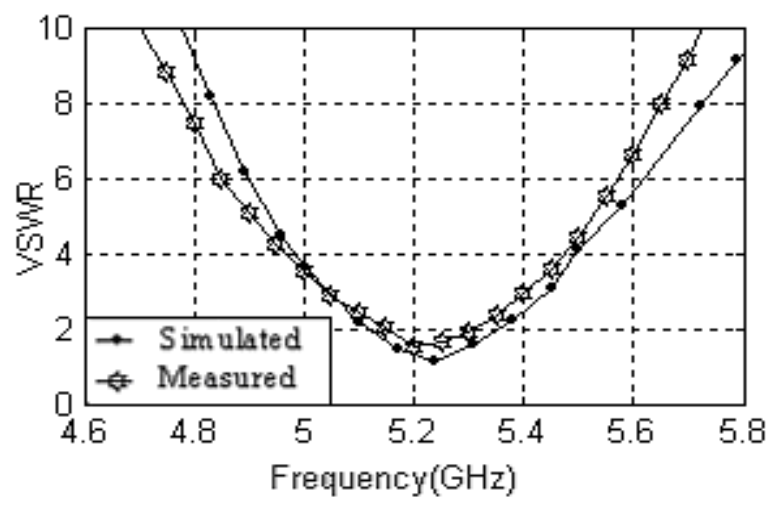

Figure 12. VSWR simulated and measured 


\section{B. Return Loss and other Characteristics.}

The return loss (shown in Figure 13) of the antenna is $-26 \mathrm{~dB}$ at $5.25 \mathrm{GHz}$ and from RL curve, the bandwidth obtained for RL $>-9.5 \mathrm{~dB}$ is $180 \mathrm{MHz}$. The measured value of VSWR, obtained from the curve is 1.5 .

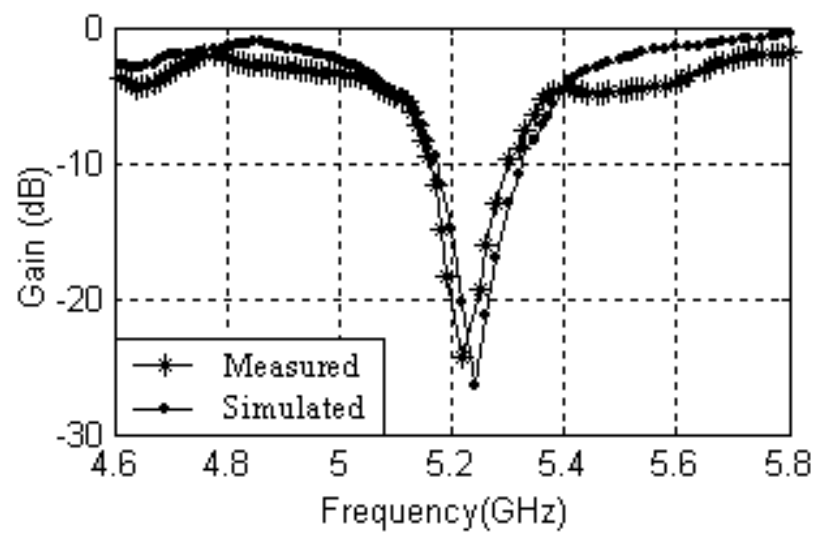

Figure 13. Return Loss curve at $5.25 \mathrm{GHz}$.
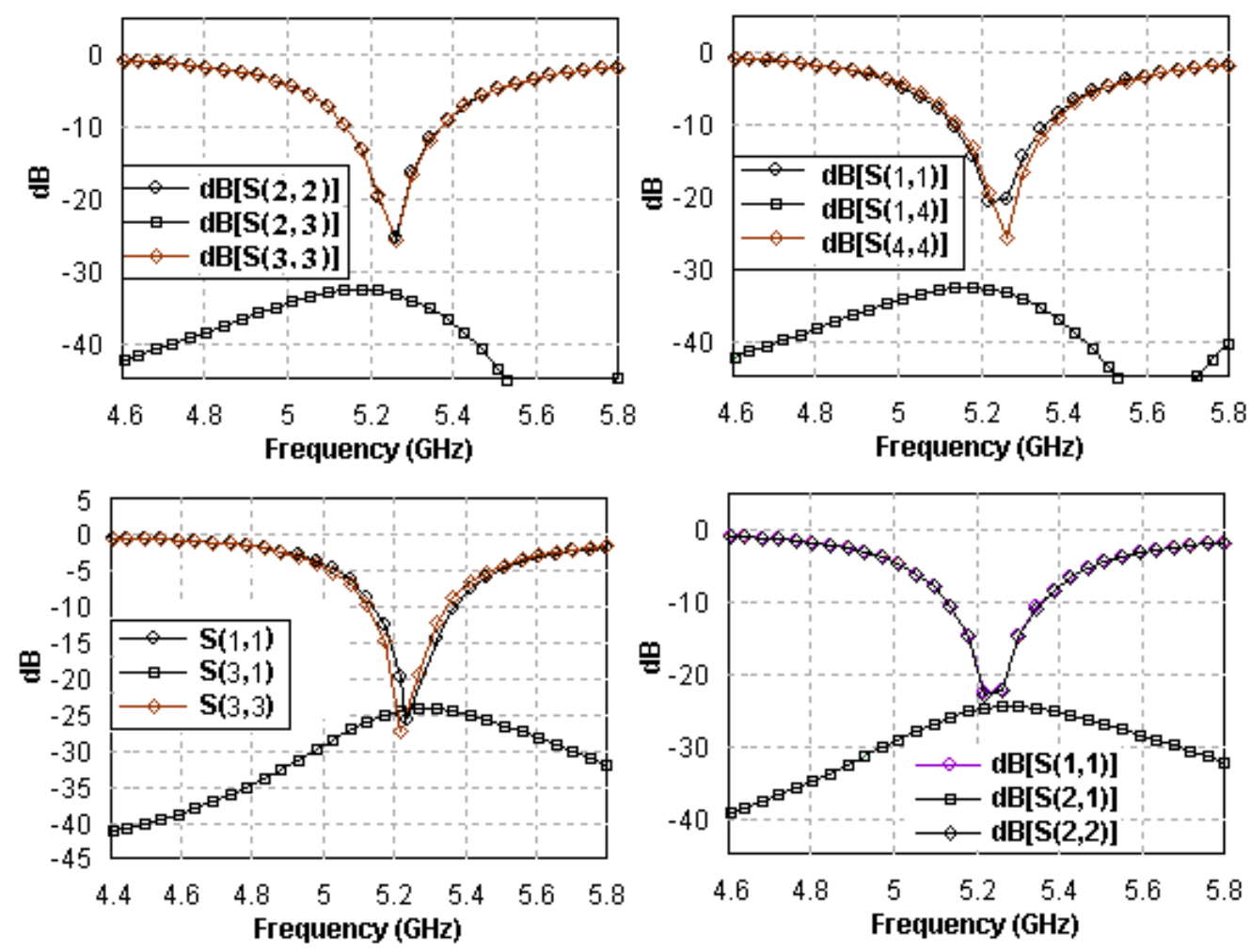

Figure 14. Simulated results of S-parameter keeping the distance between the elements of $3.0 \mathrm{~cm}$. 
Figure 15 shows the isolation between two antenna elements obtained from the simulations and the measured results of isolation between each pair of antenna elements at $\mathrm{x}_{1}$ of $3.0 \mathrm{~cm}$ $(0.526 \lambda)$ are illustrated in the Figure 16. In this investigation, isolation of more than $23 \mathrm{~dB}$ for each pair of elements has been achieved that causes very low mutual coupling. Isolation of more than $20 \mathrm{~dB}$ for each pair of antenna elements needs to maintain for low mutual coupling and this can be achieved when the separation between the antenna elements is at least $0.5 \lambda$ $[13,14]$. In case of S12 parameters three different distances between the antenna elements of $3.0 \mathrm{~cm}(0.526 \lambda), 2.5 \mathrm{~cm}(0.44 \lambda)$ and $2.0 \mathrm{~cm}(0.35 \lambda)$ respectively have been considered to optimize $\mathrm{x}_{1}$. In this design, the optimized value of $\mathrm{x}_{1}$ is $3.0 \mathrm{~cm}(0.526 \lambda)$.

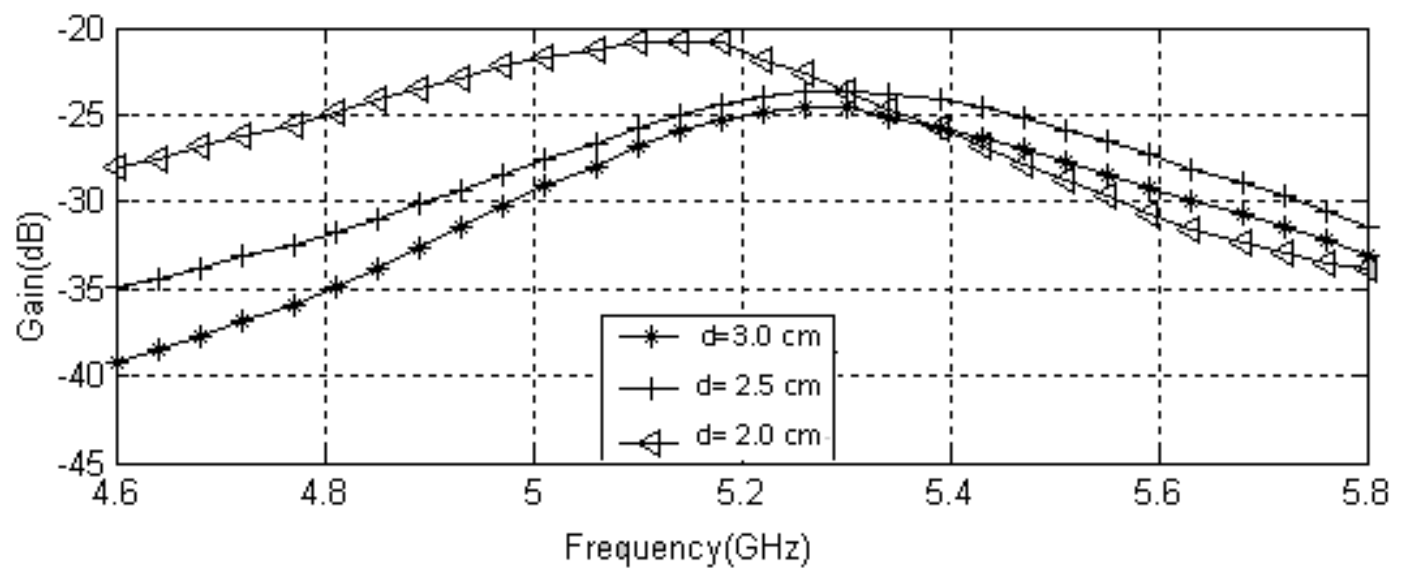

Figure 15. Simulated results of S12 between two adjacent antenna elements for three different $x_{1}$ value.

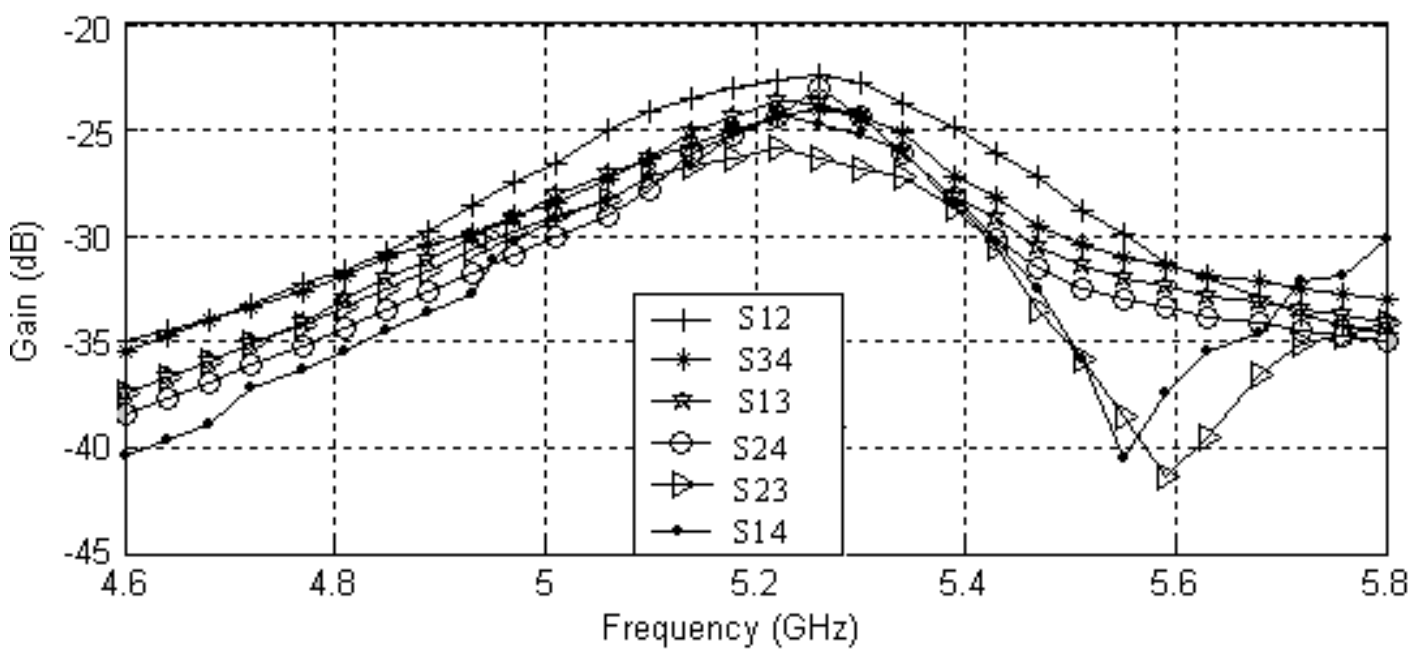

Figure 16. Measured results of S-parameters for $\mathrm{x}_{1}=0.526 \lambda$ 


\section{Conclusion}

The proposed slotted microstrip antenna array is electrically small and suitable to handle easily. From the results it is observed that the maximum gain obtained in the broadside direction and the peak gain at design frequency for the array is $13.88 \mathrm{dBi}$ for both $\varphi=0$ degree and $\varphi=90$ degree. The measured value of RL $(<-25 \mathrm{~dB})$ and VSWR $(<1.5)$ fairly tallied with the simulated result. If the dielectric constant is high, the electrical length of the antenna will be reduced but the bandwidth would be narrow.

In this investigation, the B.W of $180 \mathrm{MHz}$ and isolation between the antenna elements of less than $-25 \mathrm{~dB}$ has been achieved. It is clearly observed that the impedance bandwidth, radiation efficiency improved significantly by employing proposed (2x2) array antenna. In case of single element it has been observed that the antenna gain is quite low. But while employing the array, gain increases significantly. This is one of the most advantages of the array structure. All S-parameters have been studied by inserting the feed point to each element separately.

\section{References}

[1] K. Fujimoto and J.R. James, Mobile antenna system handbook, $2^{\text {nd }}$ edition, Artech House Inc., 2001

[2] Gonca CAKIR,Levent SEVGI, “ Design, Simulation and Tests of a Low-cost Microstrip Patch Antenna Arrays for the Wireless Communication", Turk J Elec. Engin, Vol. 13. No. 12005.

[3] R. G. Vaughan and J.B. Anderson, "Antenna Diversity in Mobile Communications," IEEE Trans. Antennas and Propagation, vol. 49,no. , pp. 954-960, June 1987.

[4] E. Siachalou, E. Vafiadis, Sotorios S, Goudos, T. Samaras, C. S. Koukourlis, and Stavros Panas, "On theDesign of Switched Beam Wideband Base Stations", IEEE Antennas and Propagation Magazine, Vol. 46,No. 1, pp. 158-167,February 2004.

[5] R. Comitangelo, D. Minervini, B. Piovano, "Beam Forming Networks of Optimum Size and Compactnessfor Multibeam Antennas at $900 \mathrm{MHz}$ ", IEEE Antenna and Propagation International Symposium, Vol. 4, pp.2127-2130, July, 1997.

[6] Mailoux, R. J. and J. F. Mcilvenna, 1981. Microstriparray technology. IEEE Trans. Antennas and Propagation, AP: 29.

[7] Shun-Yun Lin and Kuang-Chih Huang, "A compact Microstrip Antenna for GP and DCS Application”, IEEE Trans. AntennasPropag., vol. 53, No.3, pp. 1227-1229, March. 2005.

[8] Gijo Augustin, P. C. Bybi, V. P. Sarin, P. Mohanan, C. K. Aanandan, and K. Vasudevan, "A Compact Dual-Band Planar Antenna for DCS-1900/PCS/PHS, WCDMA/IMT-2000, and WLAN Applications", IEEE Antennas WirelessPropag. Lett., vol. 7, pp. 108111,2008

[9] Ely Levine, Gabi Malamud, David Treves "AStudy of Microstrip Array Antennas with theFeed Network" IEEE Transactions on Antennas and Propagation, Vol. 37, No.4,1989.

[10] Su, S. W. and J. H. Chou, "Low cost flat metal-plate dipoleantenna for 2.4/5-GHz WLAN operation," Microw. Opt. Tech.Lett., Vol. 50, 1686-1687, 2008.

[11] R. A. Sainati CAD of micro strip antenna for wireless applications. Artech House, Inc.1996.

[12] W. L. Stutzman. Antenna Theory \& Design. John Willy \& son's ine Second edition 1998.

[13] Styeskal, H. and J. S. Herd, "Mutual coupling compensation in small array antennas," IEEE Trans. AP, Vol. 38, No. 12, 1971-1975, Dec. 1990.

[14] A. Gorokhov, D. A. Gore, and A. J. Paulraj," Receive antenna selection of MIMO flatfading channel: Theory and algorithms, "IEEE Trans. Inform. Theory, vol.49, pp. $2867-$ 2896, Oct.2003 


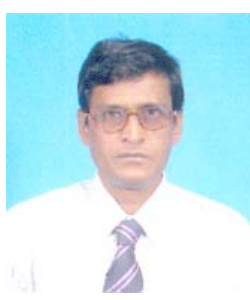

Chandan Kumar Ghosh received the B.Sc (Hons) degree in Physics and B.Tech. degree in Radio physics and Electronics from University of Calcutta in the year 1987 and 1990 respectively. He did M. Tech. degree in Microwave Engineering in the year 2003, from Burdwan University, India. From 1991 to 1995, he worked as Development Engineer in Sonodyne Electronics Co. Pvt. Ltd. and from 1996 to 1999 he worked as Assistant Manager (R\&D) in Sur Iron \& Steel Co. Pvt. Ltd. From 2000 to 2009 he was associated with the department of Electronics \& communication Engineering of Murshidabad College of Engineering \& Technology and from Aug' 10 he is in Dr. B. C. Roy Engineering College, Durgapur, India and presently holds the post of Assistant Professor. He published more than 10 contributory papers in referred journals and international conference proceedings. His current research interests include the Array antenna, MIMO antenna, DGS, EBG etc.

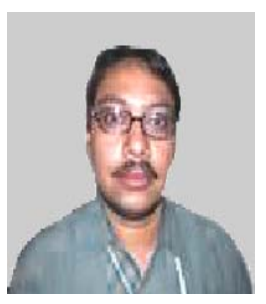

Susanta Kumar Parui received the B.Sc degree in Physics and B.Tech. degree in Radio physics and Electronics from University of Calcutta in the year 1987 and 1990 respectively. He did Master and Ph. D in Microwave Engineering from Bengal Engineering and Science University, Shibpur, India. From 1993 to 2000, he worked as Instrument Engineer in Process control Industries. Since 2000, he is associated with the department of Electronics and Telecommunication Engineering of Bengal Engineering and Science University, India and presently holds the post of Assistant Professor. He was awarded post doctorial fellowship from Royal Academy of Engineering, U.K in the year 2009. His current research interests include the planar circuits, antennas, SIW, DGS, EBG and Meta materials. He published more than 40 contributory papers in referred journals and international conference proceedings. 